\title{
The peptide compound urantide regulates collagen metabolism in atherosclerotic rat hearts and inhibits the JAK2/STAT3 pathway
}

\author{
TU WANG ${ }^{*}$, XIAOXU SUN ${ }^{*}$, HAIPENG CUI, KAI LIU and JUAN ZHAO \\ Department of Pathophysiology, Chengde Medical University, Chengde, Hebei 067000, P.R. China
}

Received March 23, 2019; Accepted November 11, 2019

DOI: $10.3892 / \mathrm{mmr} .2020 .10934$

\begin{abstract}
The aim of the present study was to investigate the effect of urantide on collagen metabolism in the hearts of rats with atherosclerosis (AS) by evaluating the expression of Janus kinase 2 (JAK2)/signal transducer and activator of transcription 3 (STAT3) pathway constituents. Urantide was delivered to rats with AS via tail vein injection for 3, 7 and 14 days. Serological indicators were identified by an automated biochemical analyzer. Histomorphological changes in the cardiac tissue of rats were observed by pathological staining techniques. The expression of genes and proteins was assessed using reverse transcription-quantitative PCR and western blot analysis, respectively. Localization of proteins was detected by immunofluorescence. Overexpression of urotensin II (UII) and its receptor, G protein-coupled receptor 14 (GPR14), was observed in the hearts of rats with AS and the expression of both proteins significantly declined after urantide administration. Triglyceride, total cholesterol, low-density lipoprotein, high-density lipoprotein and calcium levels were improved in rats with AS following treatment with urantide. Notably, urantide was able to antagonize the UII/GPR14 system. Urantide treatment resulted in markedly decreased expression levels of matrix metalloproteinase 2 (MMP-2), collagen type I/III, and genes and proteins in the JAK2/STAT3 pathway. By contrast, TIMP metallopeptidase inhibitor 2 (TIMP-2) levels were increased. In addition, the MMP-2/TIMP-2 protein ratio was significantly decreased in rats treated with urantide compared with AS rats with no urantide treatment. Constituents of the JAK2/STAT3 pathway and collagen type I/III were found to be localized in the diseased tissue and blood vessels of the hearts of rats with
\end{abstract}

Correspondence to: Dr Juan Zhao, Department of Pathophysiology, Chengde Medical University, 1 Anyuan Road, Chengde, Hebei 067000, P.R. China

E-mail: zhaojuan@cdmc.edu.cn

*Contributed equally

Key words: urantide, atherosclerosis, urotensin II, collagen metabolism, myocardial fibrosis, Janus kinase 2/signal transducer and activator of transcription 3 pathway
AS. In conclusion, urantide was able to effectively block the UII/GPR14 system by regulating the JAK2/STAT3 pathway and collagen metabolism. Inhibition of the UII/GPR14 system may prevent and potentially treat atherosclerotic myocardial fibrosis. Based on the current results, it was hypothesized that collagen metabolism may be associated with the JAK2/STAT3 pathway.

\section{Introduction}

Atherosclerosis (AS) is a serious disease that causes hypoxic ischemia of the heart and leads to disordered collagen metabolism during its progression $(1,2)$. Multiple studies have revealed that the urotensin II/urotensin report (UII/UT) system, which is composed of UII and its receptor, G protein-coupled receptor 14 (GPR14), serves an important role in various diseases, including AS and heart disease $(3,4)$. Therefore, the prevention and treatment of AS via regulation of the UII/UT system may prove to be effective for the improvement of myocardial collagen metabolism disorders.

The Janus kinase/signal transducer and activator of transcription (JAK/STAT) pathway is a key cytokine signaling pathway that regulates various pathophysiological processes, including inflammation and myocardial fibrosis (5-7). In addition, the proteolytic enzymes matrix metalloproteinase (MMP) and tissue inhibitor of matrix metalloproteinase can regulate the expression of collagen, which serves an important role in myocardial fibrosis and cardiac dysfunction (8). Study has reported that the JAK2/STAT3 pathway, MMP-2 and MMP-9 are strongly associated with the prevention of myocardial injury by reducing inflammation and fibrosis (9). In the present study, the state of collagen metabolism disorders was monitored in rats with AS by observing changes in the JAK2/STAT3 pathway and the MMP-2/TIMP metallopeptidase inhibitor 2 (TIMP-2) protein ratio.

Urantide, a UII receptor antagonist derived from human UII (hUII), competitively antagonizes the contraction of the rat thoracic aorta and the mitogenic effect of UII on vascular smooth muscle cells $(10,11)$. The main reason for conducting the present study was the fact that little research regarding the association between the effects of urantide on the prevention and treatment of AS and AS-related heart disease has been performed. Based on the successful replication of an AS rat model, it was demonstrated that urantide was able to significantly reduce myocardial fibrosis in rats with AS. This effect 
may have been associated with the JAK2/STAT3 pathway and the MMP-2/TIMP-2 protein ratio.

\section{Materials and methods}

Animals and treatment groups. A total of 200 Wistar male rats (age, 4 weeks) weighing 180-200 g were obtained from Charles River Laboratories, Inc. and housed at a constant temperature of $22 \pm 2^{\circ} \mathrm{C}$ with a humidity of $40-60 \%$ and under a 12-h light/dark cycle. The rats were randomly divided into two groups: A normal control group consisting of 40 rats and an AS model preparation group consisting of 160 rats. Rats in the normal control group were supplied with normal feed daily and rats in the AS model preparation group followed a high-fat diet according to an AS rat preparation method, as previously described $(12,13)$. The high-fat diet was purchased from Beijing Keao Xieli Feed Co., Ltd. The experimental period lasted 4 weeks.

An AS rat model was established by intraperitoneal (i.p.) injection of $150 \mathrm{U} / \mathrm{kg}$ vitamin $\mathrm{D}_{3}$ (Harbin Huasheng Science and Technology Animal Medicine Factory) for 3 days, and rats were continuous feeding a high-fat diet to damage the arterial intima (14). In the fourth week, 10 rats from each of the two experimental groups were randomly sacrificed by i.p. injection of sodium phenobarbital $(150 \mathrm{mg} / \mathrm{kg})$ in order to detect whether the AS rat model had been successfully replicated. Subsequently, the rats with AS were randomly divided into the following groups: i) An AS model group (30 rats); ii) a simvastatin group (30 rats); and iii) three urantide groups (30 rats in each of the three subgroups). Saline $(30 \mu \mathrm{g} / \mathrm{kg})$ was injected into the tail veins of rats in the normal control group and the AS model group for 14 consecutive days. Rats in the simvastatin group were intraperitoneally injected with $5 \mu \mathrm{g} / \mathrm{kg}$ simvastatin (Lunan Beite Pharmaceutical Co., Ltd.) for 14 days. Urantide (30 $\mu \mathrm{g} / \mathrm{kg}$; Shanghai Qiangyao Biological Technology Co., Ltd.) was injected into the tail veins of rats with AS in the three urantide groups daily for 3, 7 and 14 days, respectively. In the present study, the dosages of simvastatin and urantide were based on two preliminary studies by Zhao et al $(10,11)$. The rats were given ad libitum access to food and water. The experimental design is presented in Fig. 1.

Sample collection and testing. All rats were sacrificed using $150 \mathrm{mg} / \mathrm{kg}$ sodium pentobarbital (Tianjin Fuchen Chemical Co., Ltd.). The rat abdominal aortas were punctured to obtain blood, and following centrifugation at $1,500 \mathrm{x} \mathrm{g}$ for $10 \mathrm{~min}$ at $4^{\circ} \mathrm{C}$, the supernatant was stored at $-20^{\circ} \mathrm{C}$. In the present study, automated biochemical analysis (BS-480; Shenzhen Mindray Bio-Medical Electronics Co., Ltd.) at Hebei Province 266 Hospital was performed to determine triglyceride (TG), total cholesterol (TC), low-density lipoprotein (LDL), high-density lipoprotein (HDL) and calcium $\left(\mathrm{Ca}^{2+}\right)$ levels.

Morphological evaluation. The thoracic aortas and hearts were dissected from the rats and divided into two parts; one part was fixed with $4 \%$ paraformaldehyde at $4{ }^{\circ} \mathrm{C}$ for $24 \mathrm{~h}$ for morphological examination, while the other part was stored directly in liquid nitrogen for molecular biological detection.

Paraffinized, $4.5-\mu \mathrm{m}$ sections of rat thoracic aortas and cardiac tissue were prepared and hematoxylin and eosin (H\&E) staining (Nanchang Yulu Experimental Equipment Co., Ltd.) was performed according to the manufacturer's instructions. A total of 10 heart sections were randomly selected from each group. Each section was examined for evidence of mononuclear and polymorphic cell infiltration, necrosis and mineralization and given a histological score of 0 to 4 as follows: i) 0 , no change; ii) 1 , changes found in $0-25 \%$ of cells; iii) 2 , changes found in $26-50 \%$ of cells; iv) 3 , changes found in $51-75 \%$ of cells; and v) 4, changes found in 76-100\% of cells (15).

Masson trichrome staining and immunolocalization. Collagen content in the cardiac tissue was determined using Masson trichrome staining (Fuzhou Maixin Biotech Co., Ltd.). The ratio of collagen positive area to total area was calculated using a computer imaging system. The distribution of phosphorylated (p)-JAK2 (cat. no. ab32101; Abcam), p-STAT3 (phosphorylated-STAT3; cat. no. 9145; Cell Signaling Technology, Inc.) and collagen type I/III (cat. no. bs-0578R/0948R; Bioss) proteins was determined using immunofluorescence. The isolated paraffinized heart sections were dewaxed by xylene, and following their dehydration, stained for collagen at $22 \pm 2^{\circ} \mathrm{C}$ for $5 \mathrm{~min}$ and incubated with antibodies against p-JAK2 (cat. no. ab32101; Abcam) and p-STAT3 (cat. no. 9145; Cell Signaling Technology, Inc.) and collagen type I/III (cat. no. bs-0578R/0548R; BIOSS) at 1:300 at $4^{\circ} \mathrm{C}$ for $12 \mathrm{~h}$ according to a standard protocol (16). Next, the sections which were immunoblotted for p-JAK2/p-STAT3 and collagen type I/III were incubated with FITC-labeled goat anti-rabbit IgG antibody (cat. no. A0562; Beyotime Institute of Biotechnology) at $1: 1,000$ at $37^{\circ} \mathrm{C}$ for $60 \mathrm{~min}$. Then, the myocardial collagen volume $(\%)$ was calculated using Image-Pro Plus 6.0 software (Media Cybernetics, Inc.). Images were captured using a fluorescence microscope (Olympus Corporation).

Quantification of $m R N A$ expression levels by reverse transcription-quantitative PCR ( $R T-q P C R)$. Total RNA was extracted from the cardiac tissues using TRIzol ${ }^{\circledR}$ reagent (Invitrogen; Thermo Fisher Scientific, Inc.) and quantified by UV spectrophotometry. Subsequently, total RNA was reverse transcribed into cDNA using a FastQuant RT kit (Tiangen Biotech Co., Ltd.) at $42^{\circ} \mathrm{C}$ for $15 \mathrm{~min}$ and $95^{\circ} \mathrm{C}$ for $3 \mathrm{~min}$. qPCR was subsequently performed using the SuperReal PreMix Plus (SYBR Green) fluorescence quantitative premixing kit (Tiangen Biotech Co., Ltd.). The related gene primers were synthesized by Takara Biotechnology Co., Ltd. and their respective sequences are presented in Table I. According to the manufacturer's protocol, the following thermocycling conditions were used for qPCR: $95^{\circ} \mathrm{C}$ for $15 \mathrm{~min}$, followed by 40 cycles of $95^{\circ} \mathrm{C}$ for $10 \mathrm{sec}$ and $60^{\circ} \mathrm{C}$ for $32 \mathrm{sec}$. mRNA expression levels were quantified using the $2^{-\Delta \Delta \mathrm{Cq}}$ method and normalized to the internal reference gene $\beta$-actin $(17,18)$.

Western blot analysis. Western blotting was conducted to evaluate cardiac protein expression. Total protein was extracted from the heart tissue using RIPA protein lysate (Beijing Solarbio Science \& Technology Co., Ltd.). Protein content was quantified using the bicinchoninic acid Protein Concentration assay kit (Beijing Solarbio Science \& Technology Co., Ltd.). A total of $45 \mu \mathrm{g}$ protein/lane was separated via $8 \%$ SDS-PAGE 


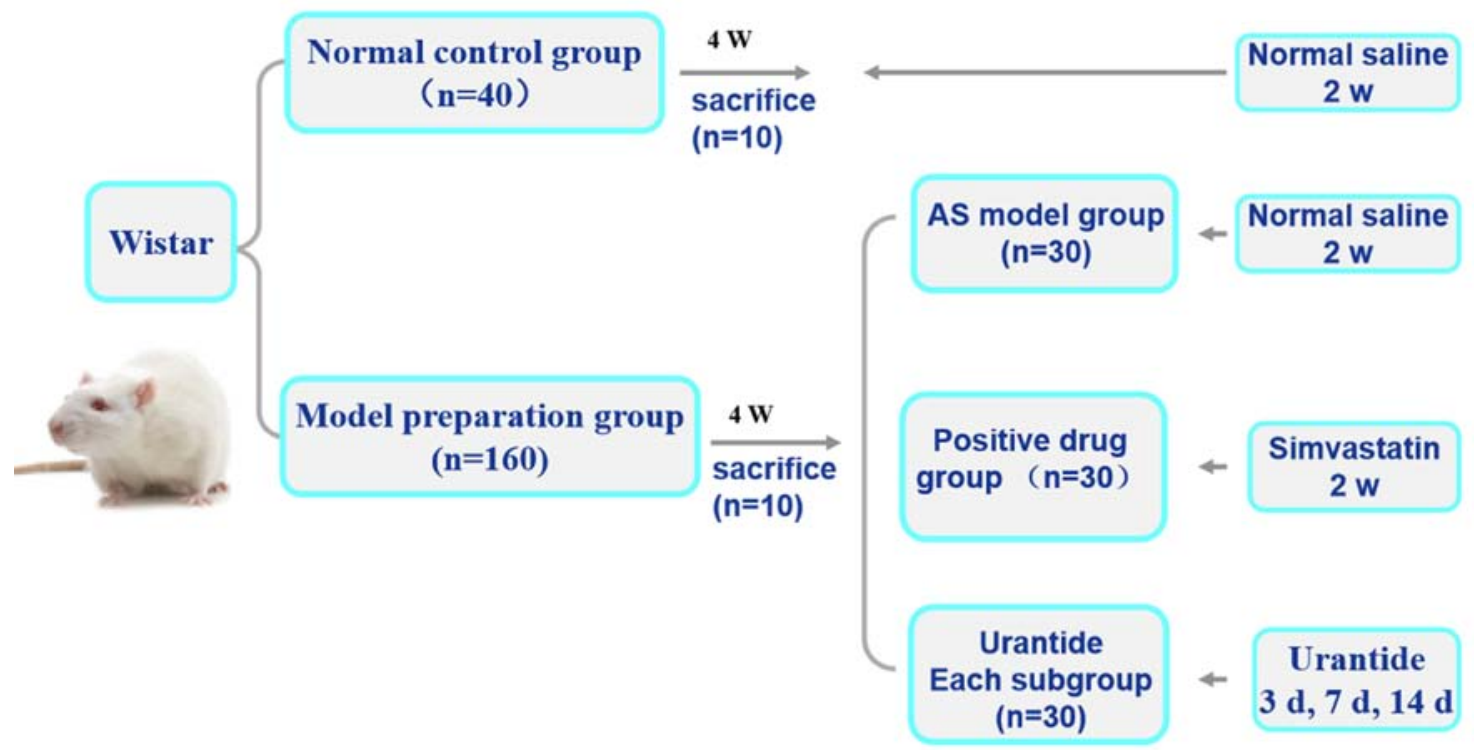

Figure 1. Experimental design. The setting of the experimental group, the interventions of each group and the intervention time. AS, atherosclerosis; w, weeks; d, days; n, number.

and transferred to an immobilon-P PVDF membrane, which was blocked with $5 \%$ skimmed milk powder at $22 \pm 2{ }^{\circ} \mathrm{C}$ for $1.5 \mathrm{~h}$. Next, the membrane was incubated with primary antibodies against UII (cat. no. orb352970; Biorbyt Ltd.), GPR14 (cat. no. sc-514460; Santa Cruz Biotechnology, Inc.) and p-STAT3 (cat. no. 9145; Cell Signaling Technology, Inc.) at a 1:800 dilution; JAK2 and STAT3 (cat. nos. 380903 and 310003; http://www.zen-bio.cn/; Zen Bioscience) at a 1:500 dilution; p-JAK2 (cat. no. ab32101; Abcam) and MMP-2/TIMP-2 (cat. no. BS1236/1366; https://www. bioworlde.com/Search.aspx?keyword $=1366 \&$ Category $=233 \&$ $\mathrm{x}=7 \& \mathrm{y}=10$; Bioworld Technology, Inc.) at a 1:1,000 dilution; collagen type I/III (cat. no. bs-0578R/0548R; Bioss) at a 1:500 dilution; or GAPDH (cat. no. bs-10900R; Bioss) at a 1:1,000 dilution at $4^{\circ} \mathrm{C}$ for $14-16 \mathrm{~h}$. The membranes were washed with TBST (0.1\% Tween-20; Beijing Solarbio Science \& Technology Co., Ltd.) three times and then incubated with horseradish peroxidase-labeled goat anti-rabbit or anti-mouse secondary antibodies (cat. no. 074-1056/074-1086; KPL, Inc.) at a 1:5,000 dilution at room temperature for $1 \mathrm{~h}$. Protein bands were visualized using a hypersensitive ECL chemiluminescence kit (Beyotime Institute of Biotechnology). The intensities of each protein band were analyzed using Image-Pro Plus software (version 6.0; Media Cybernetics, Inc.) with GAPDH as the loading control.

Statistical analysis. Data are expressed as the mean \pm SEM of the mean of $\geq 3$ independent experiments and were analyzed using SPSS software (version 20; IBM Corp.). The serum index contents, and gene and protein expression levels in each group of rats were analyzed by one-way analysis of variance followed by Tukey's post hoc test. Cardiac injury scores were analysed by Friedman followed by Nemenyi post hoc test for multiple comparisons. GraphPad Prism (version 7; GraphPad Software, Inc.) software was used to generate the charts. $\mathrm{P}<0.05$ was considered to indicate a statistically significant difference.

\section{Results}

Assessing the rat model of AS. After 4 weeks, the thoracic aortas dissected from rats in the AS model preparation group were found to contain diverse characteristics typical of AS lesions, in contrast to the thoracic aortas of rats in the normal control group. These characteristics included: i) Intimal inflammatory cell infiltration; ii) obvious calcification; iii) vascular smooth muscle cell proliferation and disorder; iv) foam-like cell formation; v) elastic fiber degeneration; and vi) rupture and disintegration. The specific results from $H \& E$ staining are presented in Fig. 2.

Blood lipid and $\mathrm{Ca}^{2+}$ levels. Compared with the levels in the normal group, the serum TG, TC, LDL and $\mathrm{Ca}^{2+}$ levels in the AS model preparation group were significantly increased, whereas HDL levels were decreased. Furthermore, the serum TG, TC, LDL and $\mathrm{Ca}^{2+}$ levels in the simvastatin and urantide groups were obviously decreased, in contrast to the HDL content, which was significantly increased. It was revealed that urantide and simvastatin significantly improved blood lipid and $\mathrm{Ca}^{2+}$ levels in rats with $\mathrm{AS}$. The specific results are displayed in Table II.

Cardiac pathological changes in rats with AS. Morphological methods were employed to assess AS-related cardiac damage and collagen metabolism. In the normal group, neatly arranged myocardial fibers, oval-shaped and centered nuclei, no atrophy or hypertrophy of the myocardial cells, and the microscopic expression of collagen fibers were observed. By contrast, the AS model preparation group exhibited cardiomyocyte hypertrophy, interstitial fibrosis, increased neutrophil infiltration between cells, scattered foam-like cell formation, hyperemia and abundant fibers (Fig. 3A and B). Furthermore, both cardiac damage scores and myocardial collagen volumes were significantly higher in the AS model group than in the control group (Fig. 3C and D). Compared with the AS model group, the 
Table I. Primer sequences used for the reverse transcription-quantitative PCR analysis of relative mRNA expression levels.

\begin{tabular}{|c|c|c|}
\hline Gene & Species & Primer sequence $\left(5^{\prime} \rightarrow 3^{\prime}\right)$ \\
\hline UII & Rat & $\begin{array}{l}\text { F: GGAGGAGCTGGAGAGGACTG } \\
\text { R: GAGTCTCGGCACTGGGATCT }\end{array}$ \\
\hline GPR14 & Rat & $\begin{array}{l}\text { F: AATGGCTCTAGGGTCCTCCT } \\
\text { R: AACAGCCTCTGTGATGGACA }\end{array}$ \\
\hline JAK2 & Rat & $\begin{array}{l}\text { F: TTTGGATCCCTGGATACATACCTGA } \\
\text { R: TGGCACACACATTCCCATGA }\end{array}$ \\
\hline STAT3 & Rat & $\begin{array}{l}\text { F: TTTGAGACAGAGGTGTACCACCAAG } \\
\text { R: ACCACAGGATTGATGCCCAAG }\end{array}$ \\
\hline MMP-2 & Rat & $\begin{array}{l}\text { F: GGACAGTGACACCACGTGACAA } \\
\text { R: TTTCCAAAGTGCTGGCAGAATAGAC }\end{array}$ \\
\hline TIMP-2 & Rat & $\begin{array}{l}\text { F: GACACGCTTAGCATCACCCAGA } \\
\text { R: CTGTGACCCAGTCCATCCAGAG }\end{array}$ \\
\hline Collagen I & Rat & $\begin{array}{l}\text { F: CCCTGCTGGAGAAGAAGGAA } \\
\text { R: AGGAGAACCTTTGGGACCAG }\end{array}$ \\
\hline Collagen III & Rat & $\begin{array}{l}\text { F: ACTGGTGAACGTGGCTCTAA } \\
\text { R: GGACCTGGATGTCCACTTGA }\end{array}$ \\
\hline$\beta$-actin & Rat & $\begin{array}{l}\text { F: CAGGCATTGCTGACAGGATG } \\
\text { R: TGCTGATCCACATCTGCTGG }\end{array}$ \\
\hline
\end{tabular}

UII, urotensin II; GPR14, G protein-coupled receptor 14; JAK2, Janus kinase 2; STAT3, signal transducer and activator of transcription 3; MMP-2, matrix metalloproteinase 2; TIMP-2, TIMP metallopeptidase inhibitor 2; F, forward; R, reverse.

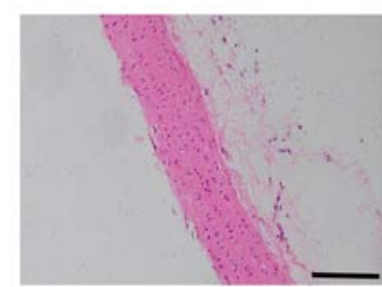

Normal

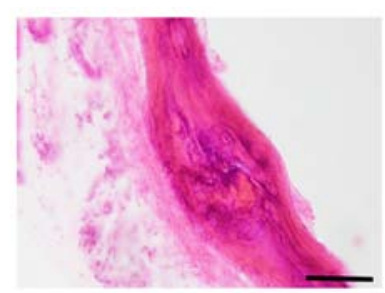

AS model
Figure 2. Histological changes in the thoracic aortas of atherosclerotic rats induced by a high-fat diet identified by hematoxylin and eosin staining. In the normal group, the arterial intima was intact and smooth, and the cells were orderly arranged. In the AS model group, atherosclerotic plaque of the intima was present and the arrangement of the cells was disordered. Scale bars, $100 \mu \mathrm{m}$. AS, atherosclerosis.

simvastatin and urantide groups were shown to have significantly reduced cardiomyocyte fibrosis and neutrophil infiltration, and lower cardiac injury scores and myocardial collagen volumes. In addition, these improvements were positively associated with treatment time and the effect of 14-day urantide treatment was similar to that observed in the positive control group.

Alterations in the expression levels of genes and proteins in cardiac tissue. Molecular biology techniques were used to detect gene and protein expression in cardiac tissue. Compared with that in the normal group, the expression of UII, GPR14, JAK2, STAT3, MMP-2 and collagen type I/III was higher in the cardiac tissue of the AS model group, whereas TIMP-2 expression was lower. Furthermore, the expression levels of
UII, GPR14, JAK2, STAT3, MMP-2 and collagen type I/III were downregulated in the cardiac tissue of rats in the urantide groups compared with the AS model group; however, TIMP-2 expression was upregulated (Fig. 4A and B). Most importantly, when the rats with $\mathrm{AS}$ received treatment, the protein ratio of p-JAK2/JAK2, p-STAT3/STAT3 and MMP-2/TIMP-2 was effectively improved as the corresponding protein ratio decreased after urantide treatment (Fig. 4Ba and C). Moreover, improved myocardial collagen metabolism was positively associated with the urantide treatment time and the effects of urantide were similar to those of the positive control drug. The specific results are shown in Fig. 4. However, the protein ratio of p-JAK2/JAK2 fluctuated at different times of urantide treatment, and the trend was consistent with serological indicators. In addition, simvastatin had little effect on the protein ratio of p-JAK2/JAK2 and p-STAT3/STAT3, as opposed to urantide treatment. Therefore, the specific mechanism underlying these effects require further study.

Localization of p-JAK2/p-STAT3 and collagen type I/III expression in cardiac tissue. Localization of the p-JAK2/ p-STAT3 and collagen type I/III proteins was determined by immunofluorescence. The expression of p-JAK2, p-STAT3, and collagen types I and III in the cardiac tissue of rats in the AS model group was increased compared with the normal group. In addition, vascular and myocardial degeneration, and necrosis were identified in the AS model group (Fig. 5). Compare with the AS model group, the expression levels of p-JAK2, p-STAT3, collagen types I and III were gradually restored in AS rats treated with urantide, which mainly 
Table II. Comparison of the levels of blood lipid components and $\mathrm{Ca}^{2+}$ in the sera of atherosclerotic and non-atherosclerotic rats.

\begin{tabular}{|c|c|c|c|c|c|}
\hline Group & $\mathrm{TC}(\mathrm{mmol} / \mathrm{l})$ & $\mathrm{TG}(\mathrm{mmol} / \mathrm{l})$ & HDL (mmol/l) & $\mathrm{LDL}(\mathrm{mmol} / \mathrm{l})$ & $\mathrm{Ca}^{2+}(\mathrm{mmol} / \mathrm{l})$ \\
\hline Normal & $2.07 \pm 0.61$ & $0.28 \pm 0.08$ & $2.95 \pm 0.93$ & $0.27 \pm 0.05$ & $2.60 \pm 0.56$ \\
\hline AS model & $11.18 \pm 3.12^{\mathrm{a}}$ & $0.77 \pm 0.12^{\mathrm{a}}$ & $0.93 \pm 0.23^{\mathrm{a}}$ & $1.70 \pm 0.31^{\mathrm{a}}$ & $3.95 \pm 0.42^{\mathrm{a}}$ \\
\hline Simvastatin & $4.06 \pm 1.51^{\mathrm{a}, \mathrm{b}}$ & $0.41 \pm 0.12^{\mathrm{b}, \mathrm{c}}$ & $2.16 \pm 0.35^{\mathrm{b}, \mathrm{c}}$ & $0.77 \pm 0.19^{\mathrm{a}, \mathrm{b}}$ & $3.63 \pm 0.13^{\mathrm{a}, \mathrm{d}}$ \\
\hline \multicolumn{6}{|c|}{ Urantide treatment } \\
\hline 3 days & $7.52 \pm 1.59^{\mathrm{a}, \mathrm{b}, \mathrm{e}}$ & $0.55 \pm 0.20^{\mathrm{a}, \mathrm{d}, \mathrm{f}}$ & $1.48 \pm 0.37^{\mathrm{a}, \mathrm{b}, \mathrm{e}}$ & $1.05 \pm 0.31^{\mathrm{a}, \mathrm{b}, \mathrm{e}}$ & $3.46 \pm 0.32^{\mathrm{a}, \mathrm{d}}$ \\
\hline 7 days & $5.28 \pm 0.59^{\mathrm{a}, \mathrm{b}, \mathrm{f}}$ & $0.37 \pm 0.15^{\mathrm{b}}$ & $1.91 \pm 0.66^{\mathrm{a}, \mathrm{d}}$ & $0.84 \pm 0.27^{\mathrm{a}, \mathrm{b}}$ & $3.22 \pm 0.29^{\mathrm{a}, \mathrm{b}, \mathrm{f}}$ \\
\hline 14 days & $8.33 \pm 1.43^{\mathrm{a}, \mathrm{b}, \mathrm{e}}$ & $0.59 \pm 0.21^{\mathrm{a}, \mathrm{f}}$ & $1.02 \pm 0.44^{\mathrm{a}, \mathrm{e}}$ & $1.27 \pm 0.27^{\mathrm{a}, \mathrm{b}, \mathrm{e}}$ & $3.68 \pm 0.30^{\mathrm{a}}$ \\
\hline
\end{tabular}

TC, total cholesterol; TG, triglycerides; HDL, high-density lipoprotein; LDL, low-density lipoprotein; $\mathrm{Ca}^{2+}$, calcium. Differences between groups were detected by an automatic biochemical analyzer (mmol/l). ${ }^{\mathrm{a}} \mathrm{P}<0.01 \mathrm{vs}$. the normal group; ${ }^{b} \mathrm{P}<0.01 \mathrm{vs}$. the AS model group; ${ }^{\mathrm{c}} \mathrm{P}<0.05$ vs. the normal group; ${ }^{\mathrm{d}} \mathrm{P}<0.05$ vs. the AS model group; ${ }^{\mathrm{e}} \mathrm{P}<0.01,{ }^{\mathrm{f}} \mathrm{P}<0.05$ vs. the simvastatin group. Data are presented as the mean $\pm \mathrm{SEM}$ ( $n=6-8$ rats in each group).
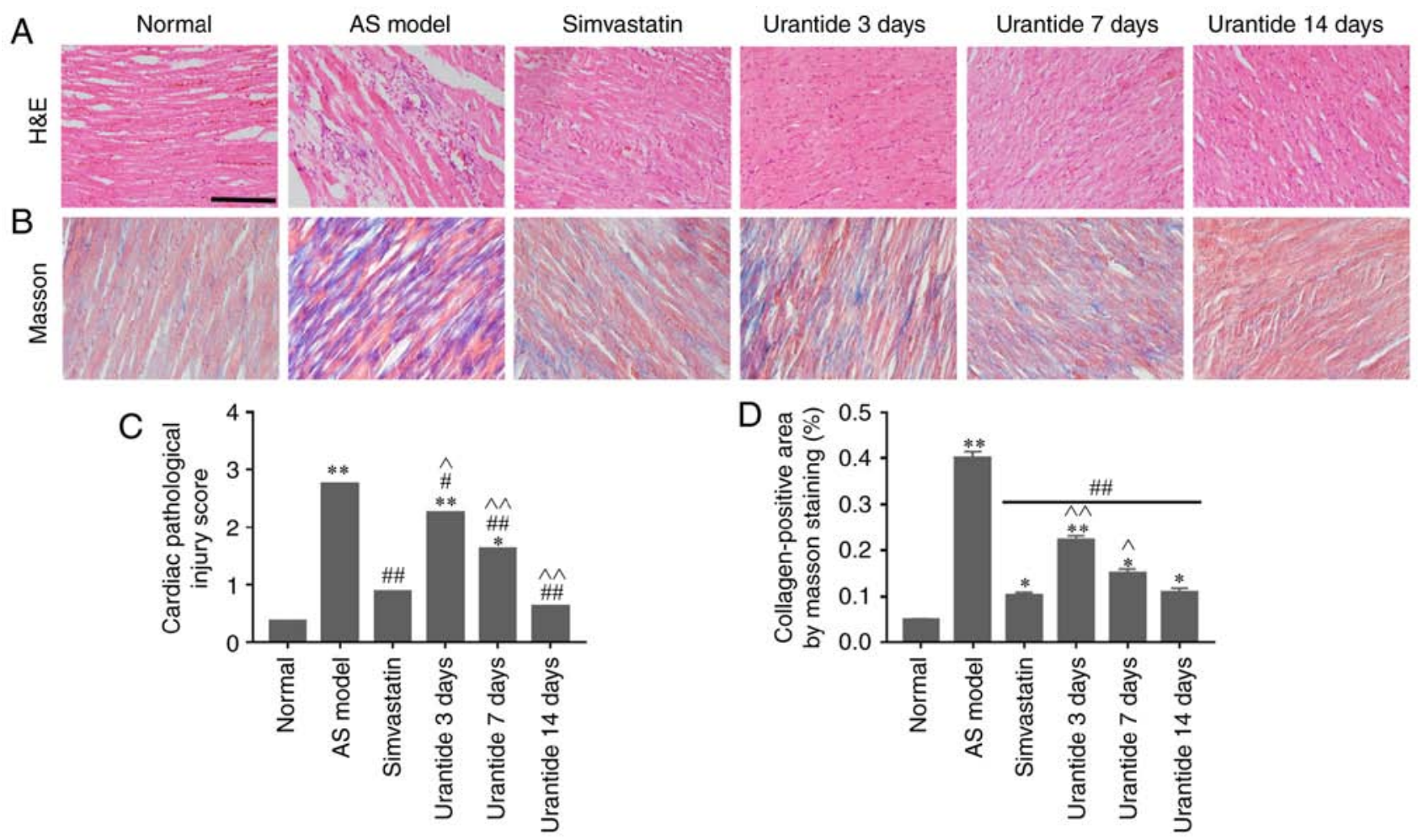

Figure 3. Alleviation of heart disease in rats with AS following urantide treatment. The following cardiac parameters improved with treatment time: (A) Pathological symptoms, (B) collagen expression, (C) cardiac pathological injury score, and (D) myocardial collagen volume. Scale bar, $50 \mu$ m. * $<0.05$, ${ }^{* *} \mathrm{P}<0.01$ vs. the normal group; ${ }^{\#} \mathrm{P}<0.05,{ }^{\# \#} \mathrm{P}<0.01$ vs. the AS model group; ${ }^{\wedge} \mathrm{P}<0.05,{ }^{\wedge} \mathrm{P}<0.01$ vs. the simvastatin group. Data are presented as the mean $\pm \mathrm{SEM}$ ( $\mathrm{n}=6-8$ rats in each group). H\&E, hematoxylin \& eosin; AS, atherosclerosis.

exhibited perivascular and myocardial degeneration and necrosis. Moreover, this effect was positively associated with treatment time.

\section{Discussion}

In the early stages of AS, type III collagen has been reported to have important compensatory effects on cardiac rearrangement and muscle bundle formation, which maintain the normal function of he tissue in the early stage of the disease $(19,20)$. However, in the advanced stages of AS, the accumulation of type I collagen in the myocardial interstitium occludes vasodilation and blood flow $(19,21)$. It was hypothesized that the effective regulation of disordered collagen metabolism may have important clinical significance in the treatment of AS.

The results demonstrated significant hyperlipidemia and myocardial hypertrophy, neutrophil infiltration, hyperemia and hemorrhage in the cardiac tissue of rats with AS, accompanied by abundant collagen. In addition, the UII/UT system in the cardiac tissue of rats with AS was activated. Luo et al (22) found that UII induces the synthesis of type I collagen fibers and promotes the occurrence of myocardial fibrosis in rats. 

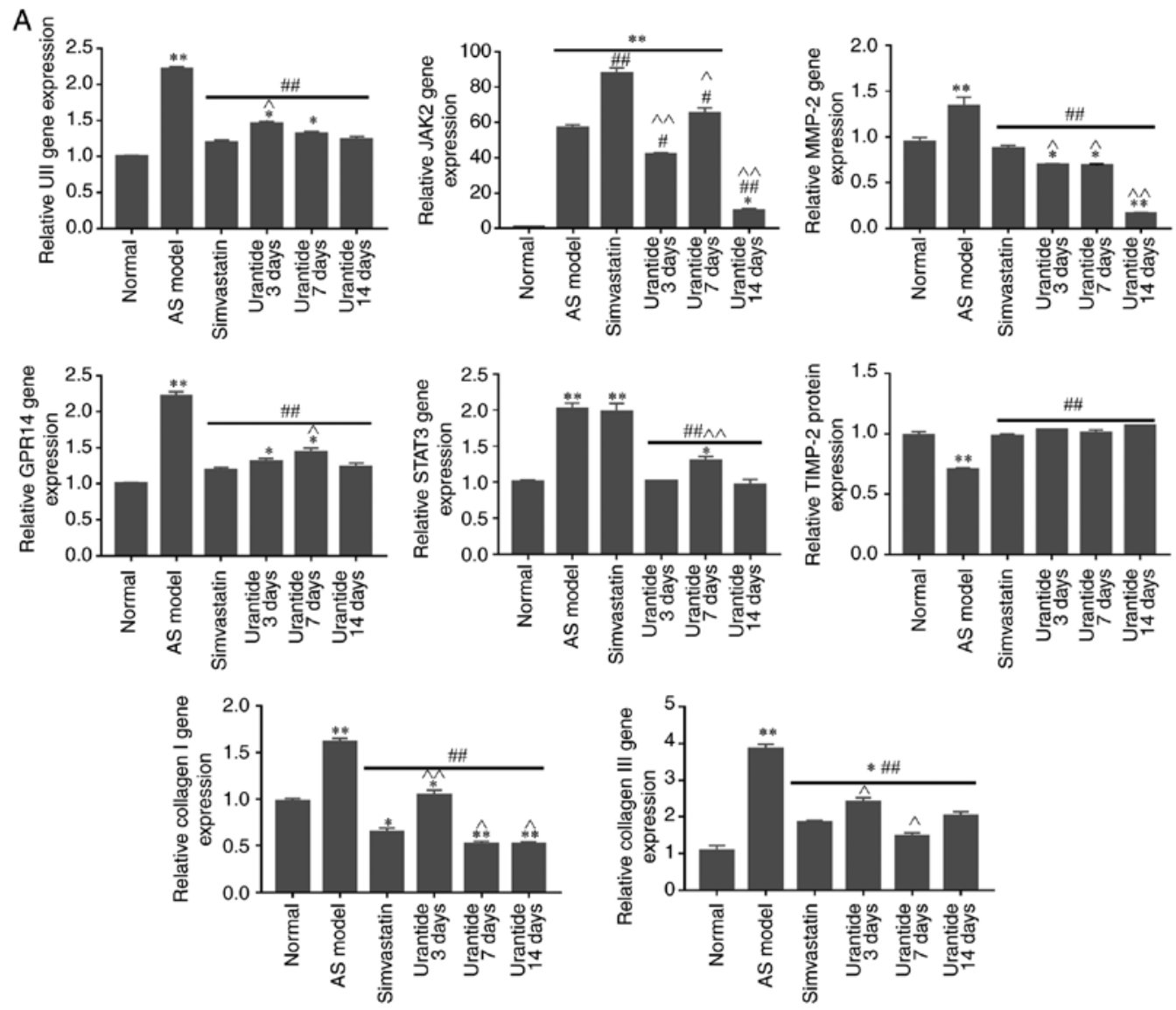

Figure 4. Effect of urantide on UII/GPR14, the JAK2/STAT3 pathway and collagen metabolism in the cardiac tissue of rats with AS. Changes in the expression of the following genes and proteins with increasing drug administration time: (A) relative expression level of genes.

Previous studies performed by the same research group have reported that urantide had a protective effect on the thoracic aortas and livers of rats with AS following inhibition of the UII/UT system $(6,23)$. The possibility of urantide treatment having a reparative effect on disordered collagen metabolism caused by AS was further investigated in the present study.

AS was shown to induce JAK2/STAT3 pathway activation and MMP-2/TIMP-2 protein ratio imbalance, consequently causing disordered collagen metabolism mainly due to increased collagen type I/III expression. This finding is consistent with results from studies on cardiac pathology and similar to the results of current studies on myocardial fibrosis $(24,25)$. Ahn et al $(26)$ reported that the JAK2/STAT3 pathway may regulate MMP-2 expression, and promote endometrial cell proliferation and migration. Furthermore, it has been demonstrated that abnormal proliferation of cardiac fibroblasts causes an imbalance in the MMP-2/TIMP-2 protein ratio, leading to disordered collagen metabolism $(27,28)$. To investigate whether inhibition of the JAK2/STAT3 pathway would ameliorate the symptoms of myocardial fibrosis, rats with AS were treated with the peptide urantide.

Recent studies identified that contrast-enhanced cardiac magnetic resonance imaging of patients with AS indicated that individuals who had a history of cardiovascular events were more likely to present with myocardial fibrosis than those who did not $(29,30)$. In the present study, disordered collagen metabolism was significantly improved in rats with AS following treatment. This effect exhibited significant time dependence. To verify the mechanism of this effect, the UII/UT system and the JAK2/STAT3 pathway were examined, and it was determined that they had undergone significant changes. The results demonstrated that urantide effectively inhibited the expression of the UII/UT system and the JAK2/STAT3 pathway. Inhibition of the JAK2/STAT3 pathway may be associated with alleviated symptoms of myocardial fibrosis, as after urantide treatment the pathological symptoms of the heart were alleviated, which is consistent with reports from relevant studies $(7,22)$. It has been reported that simvastatin is capable of reducing myocardial fibrosis by downregulating related proteins, including transforming growth factor, MMP-2, MMP-9, TIMP-1 and TIMP-2 (31). Nevertheless, studies on the relationship of simvastatin with the JAK2/STAT3 pathway are limited. Importantly, simvastatin was not found to inhibit the activation of the JAK2/STAT3 signaling pathway in the cardiac tissue of rats with AS. The results from the experiment in the present study are inconsistent with those observed following administration of simvastatin alone for the treatment of cardiac hypertrophy (32). To this end, future studies should establish a rat model of myocardial fibrosis to further explore the association of simvastatin with the JAK2/STAT3 signaling pathway.

A recent study by Cho et al (33) indicated that the JAK2/STAT3 pathway regulates MMP-2 expression, thus follow-up research was conducted on collagen mechanisms, such as changes in the expression levels of related MMPs and TIMPs after myocardial fibrosis. Another study by Wang et al (25) demonstrated that an imbalance in the 
B
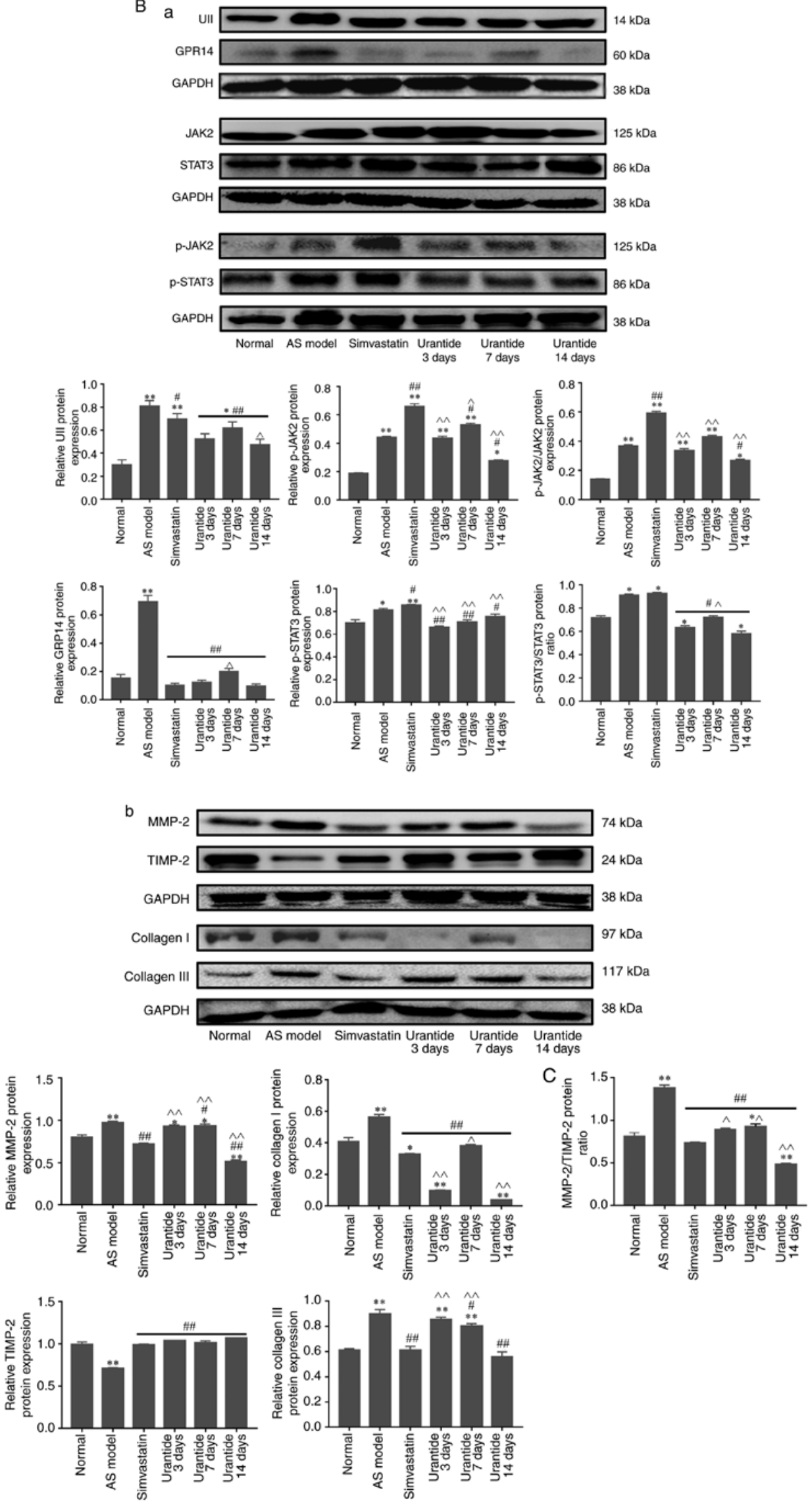

Figure 4. Continued. Changes in the expression of the following genes and proteins with increasing drug administration time: (B-a) relative expression level of signaling pathway proteins, (B-b) relative expression level of collagen metabolism related proteins and (C) MMP-2/TIMP-2 protein ratio. ${ }^{*} \mathrm{P}<0.05,{ }^{* * *} \mathrm{P}<0.01 \mathrm{vs}$. the normal group; ${ }^{\#} \mathrm{P}<0.05$, ${ }^{\# \#} \mathrm{P}<0.01$ vs. the AS model group; ${ }^{\wedge} \mathrm{P}<0.05,{ }^{\wedge} \mathrm{P}<0.01$ vs. the simvastatin group. Data are presented as the mean $\pm \mathrm{SEM}(\mathrm{n}=6-8$ rats in each group). AS, atherosclerosis; UII, urotensin II; G protein-coupled receptor 14; JAK2, Janus kinase 2; p, phosphorylated; STAT3, signal transducer and activator of transcription 3; MMP-2, matrix metalloproteinase 2; TIMP-2, TIMP metallopeptidase inhibitor 2 . 
A

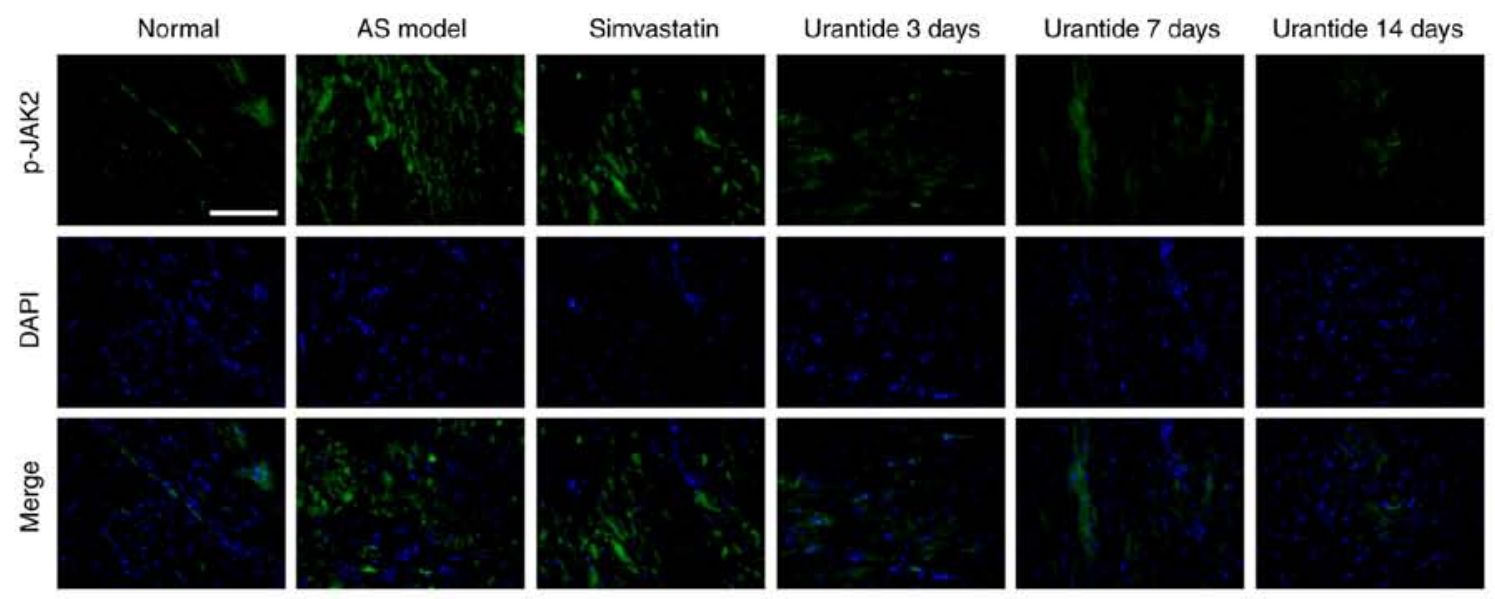

B
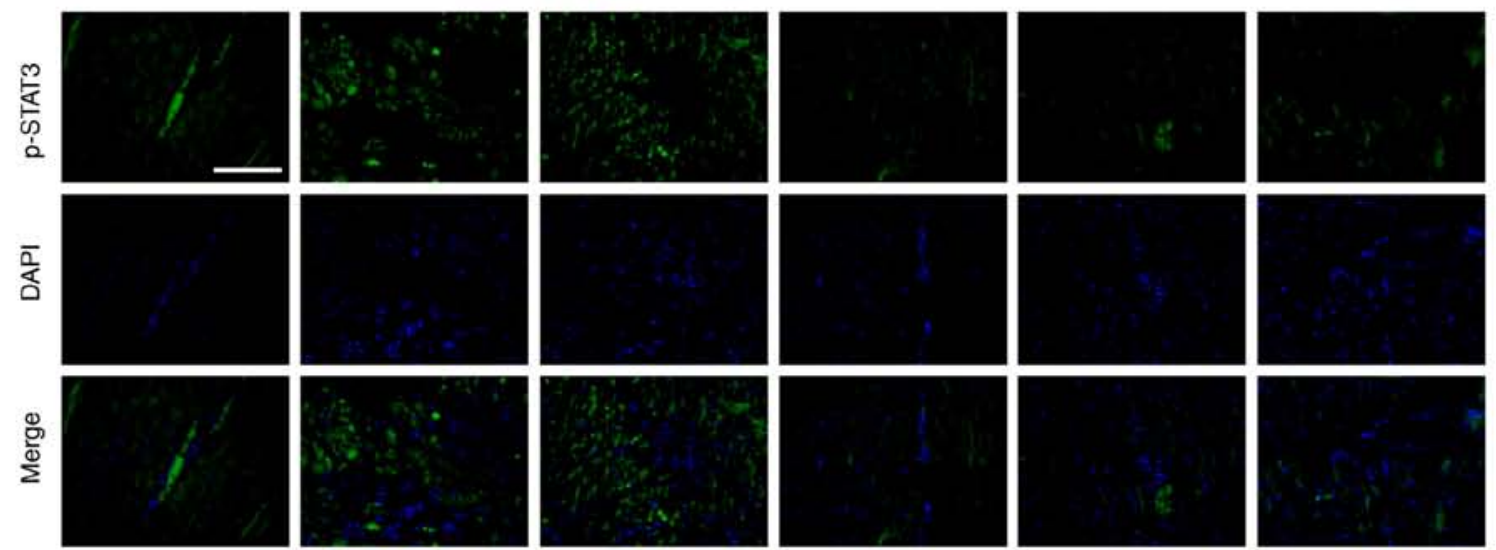

\section{C}
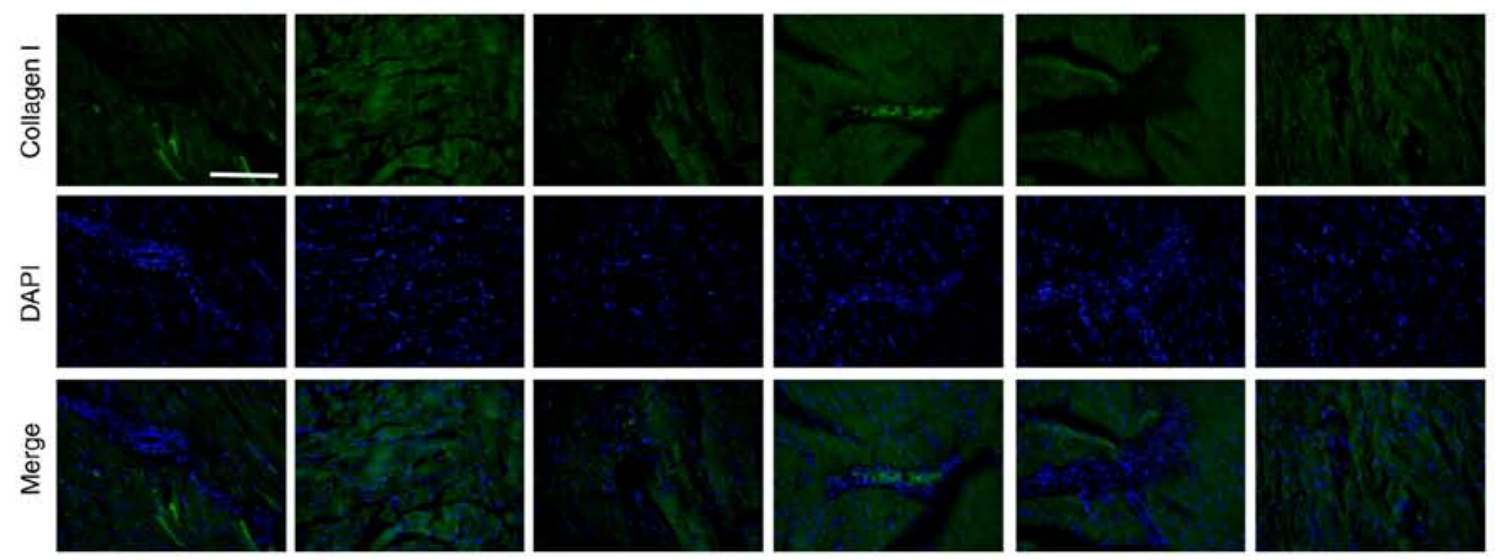

D
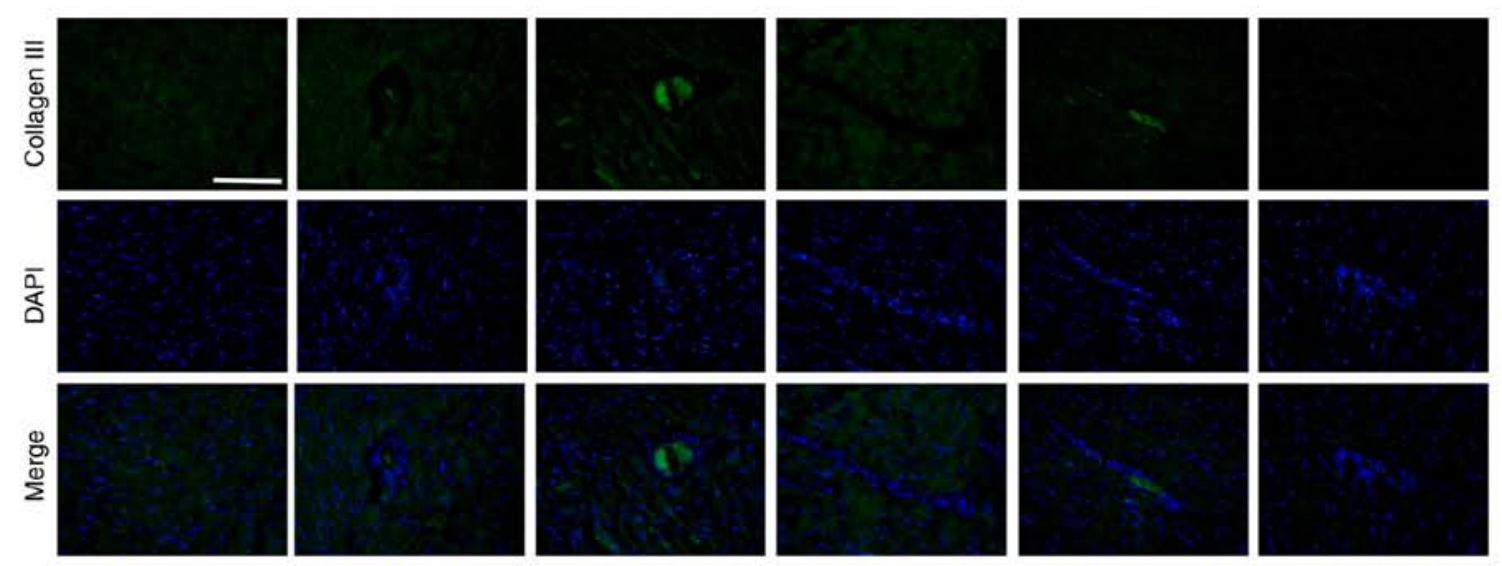

Figure 5. Effect of urantide on the distribution and localization of p-JAK2/p-STAT3 and collagen type I/III. Immunofluorescence staining of: (A) p-JAK2, (B) p-STAT3, (C) collagen I and (D) collagen III indicating the location and intensity of the positive expression of these proteins in cardiac tissue derived from each group. Scale bars, $50 \mu \mathrm{m}$. Blue, nucleus; green, positive expression. AS, atherosclerosis; p-JAK2, phosphorylated-Janus kinase 2; p-STAT3, phosphorylated-signal transducer and activator of transcription 3. 
MMP-2/TIMP-2 protein ratio affected the synthesis and degradation of myocardial collagen. In the present study, an increase in MMP-2 expression was observed in rats with AS, whereas TIMP-2 expression was decreased. Treatment with urantide for a prolonged administration time resulted in a significant improvement in the MMP-2/TIMP-2 protein ratio. By contrast, the expression levels of collagen type I/III tended to decrease. The aforementioned findings indicated that the JAK2/STAT3 pathway affected the expression of collagen type I/III by regulating the balance of MMP-2/TIMP-2, thereby alleviating the symptoms of disordered collagen metabolism.

In addition, p-JAK2/p-STAT3 and collagen type I/III were abundantly expressed in AS lesions. Urantide treatment led to a decrease in the expression and range of these proteins. Moreover, their localization indicated that the JAK2/STAT3 pathway may be involved in the process of collagen metabolism.

In summary, the treatment of rats with AS with urantide was able to relieve cardiac symptoms and also significantly improve collagen metabolism. The underlying mechanism responsible for these effects may be antagonization of the UII/UT system and inhibition of the JAK2/STAT3 pathway by urantide. This combined mechanism is capable of regulating the balance between MMP-2/TIMP-2 and decreasing collagen type I/III expression. The regulation of collagen metabolism was restored and, consequently, the degree of myocardial fibrosis in rats with AS was reduced. In addition, differences were identified in the gene and protein expression levels of collagen I between the 3- and 7-day subgroups receiving urantide treatment. These differences could be considered an asynchronous phenomenon, with differences in expression time, related to the processes of transcription and/or translation. Regarding this matter, in-depth research should be conducted to clarify the relevant mechanisms. However, whether the UII/UT system directly affects the JAK2/STAT3 pathway and how this pathway regulates collagen metabolism remains unclear. The main limitation of the present study is the lack of in vitro cell experiments examining how the UII/UT system affects the JAK2/STAT3 signaling pathway and collagen metabolism. Therefore, the downstream genes regulated by the JAK2/STAT3 pathway that directly or indirectly affect collagen metabolism should be studied to further elucidate the mechanism by which the JAK2/STAT3 pathway affects collagen metabolism.

\section{Acknowledgements}

Not applicable.

\section{Funding}

The present study was supported by the Hebei Youth Talents Project (grant. no. Hebei[2016]9), the Hebei Provincial Department of Education Outstanding Youth Fund Project (grant. no. YQ2013005) and the Key Discipline Construction Projects in Hebei Province (grant. no. Hebei[2013] 4).

\section{Availability of data and materials}

The datasets used and/or analyzed during the current study are available from the corresponding author upon reasonable request.

\section{Authors' contributions}

JZ, TW and XS designed the study. TW and XS performed the experiments. HPC and KL performed the animal model experiment. JZ, TW, XS, HC and KL analyzed the data. TW and XS wrote the manuscript. All authors critically reviewed the manuscript, and read and approved the final version of the manuscript.

\section{Ethics approval and consent to participate}

All animal procedures were ethically approved by the Experimental Animal Care and Use Committee of Chengde Medical University and were conducted in accordance with the National Institutes of Health Guide for the Care and Use of Laboratory Animals.

\section{Patient consent for publication}

Not applicable.

\section{Competing interests}

The authors declare that they have no competing interests.

\section{References}

1. Istratoaie O, OfiTeru AM, Nicola GC, Radu RI, Florescu C, Mogoant L and Streba CT: Myocardial interstitial fibrosishistological and immunohistochemical aspects. Rom J Morphol Embryol 56: 1473-1480, 2015.

2. Chen X, Tang Y, Gao M, Qin S, Zhou J and Li X: Prenatal exposure to lipopolysaccharide results in myocardial fibrosis in rat offspring. Int J Mol Sci 16: 10986-10996, 2015.

3. Ross B, McKendy K and Giaid A: Role of urotensin II in health and disease. Am J Physiol Regul Integr Comp Physiol 298: R1156-R1172, 2010.

4. Leprince J, Chatenet D, Dubessy C, Fournier A, Pfeiffer B, Scalbert E, Renard P, Pacaud P, Oulyadi H, Ségalas-Milazzo I, et al: Structure-activity relationships of urotensin II and URP. Peptides 29: 658-673, 2008.

5. Kiu H and Nicholson SE: Biology and significance of the JAK/STAT signalling pathways. Growth Factors 30: 88-106, 2012.

6. Liu M, Li Y, Liang B, Li Z, Jiang Z, Chu C and Yang J: Hydrogen sulfide attenuates myocardial fibrosis in diabetic rats through the JAK/STAT signaling pathway. Int J Mol Med 41: 1867-1876, 2018.

7. Zhao L, Wu D, Sang M, Xu Y, Liu Z and Wu Q: Stachydrine ameliorates isoproterenol-induced cardiac hypertrophy and fibrosis by suppressing inflammation and oxidative stress through inhibiting NF- $\mathrm{KB}$ and JAK/STAT signaling pathways in rats. Int Immunopharmacol 48: 102-109, 2017.

8. El Hajj EC, El Hajj MC, Voloshenyuk TG, Mouton AJ, Khoutorova E, Molina PE, Gilpin NW and Gardner JD: Alcohol modulation of cardiac matrix metalloproteinases (MMPs) and tissue inhibitors of MMPs favors collagen accumulation. Alcohol Clin Exp Res 38: 448-456, 2014.

9. Bai R, Yin X, Feng X, Cao Y, Wu Y,Zhu Z, Li C, Tu P and Chai X: Corydalis hendersonii Hemsl. protects against myocardial injury by attenuating inflammation and fibrosis via NF- $\mathrm{B}$ and JAK2-STAT3 signaling pathways. J Ethnopharmacol 207: 174-183, 2017.

10. Zhao J, Zhang SF, Shi Y and Ren LQ: Effects of urotensin II and its specific receptor antagonist urantide on rat vascular smooth muscle cells. Bosn J Basic Med Sci 13: 78-83, 2013.

11. Zhao J, Xie LD, Song CJ, Mao XX, Yu HR, Yu QX, Ren LQ, Shi Y, Xie YQ, Li Y, et al: Urantide improves atherosclerosis by controlling C-reactive protein, monocyte chemotactic protein-1 and transforming growth factor- $\beta$ expression in rats. Exp Ther Med 7: 1647-1652, 2014. 
12. Huang ZY, Yang PY, Almofti MR, Yu YL, Rui YC and Yang PY: Comparative analysis of the proteome of left ventricular heart of arteriosclerosis in rat. Life Sci 75: 3103-3115, 2004.

13. Jiao YB, Rui YC, Li TJ, Yang PY and Qiu Y: Expression of pro-inflammatory and anti-inflammatory cytokines in brain of atherosclerotic rats and effects of Ginkgo biloba extract. Acta Pharmacol Sin 26: 835-839, 2005.

14. Gou SH, Liu BJ, Han XF, Wang L, Zhong C, Liang S, Liu H, Qiang Y, Zhang Y and Ni JM: Anti-atherosclerotic effect of Fermentum Rubrum and Gynostemma pentaphyllum mixture in high-fat emulsion- and vitamin $\mathrm{D}_{3}$-induced atherosclerotic rats. J Chin Med Assoc 81: 398-408, 2018.

15. Rezkalla S, Kloner RA, Khatib FG, Smith FE and Khatib R: Effect of metoprolol in acure coxsackievirus B3 murine myocarditis. Am Coll Cardiol 12: 412-414, 1988.

16. Hayes AJ, Hughes CE and Caterson B: Antibodies and immunohistochemistry in extracellular matrix research. Methods 45: 10-21, 2008.

17. Li X, Li X, Luo R, Wang W, Wang T and Tang H: Detection of KIT Genotype in Pigs by TaqMan MGB Real-time quantitative polymerase chain reaction. DNA Cell Biol 37: 457-464, 2018.

18. Livak KJ and Schmittgen TD: Analysis of relative gene expression data using real-time quantitative PCR and the 2(-Delta Delta C(T)) method. Methods 25: 402-408, 2001

19. Collier P, Watson CJ, van Es MH, Phelan D, McGorrian C, Tolan M, Ledwidge MT, McDonald KM and Baugh JA: Getting to the heart of cardiac remodeling; how collagen subtypes may contribute to phenotype. J Mol Cell Cardiol 52: 148-153, 2012.

20. Lopez B, Gonzalez A, Hermida N, Valencia F, de Teresa E and Diez J: Role of lysyl oxidase in myocardial fibrosis: From basic science to clinical aspects. Am J Physiol Heart Circ Physiol 299: H1-H9, 2010

21. Lopez B, Gonzalez A, Varo N, Laviades C, Querejeta R and Diez J: Biochemical assessment of myocardial fibrosis in hypertensive heart disease. Hypertension 38: 1222-1226, 2001.

22. Luo SY, Chen S, Qin YD and Chen ZW: Urotensin-II Receptor antagonist SB-710411 protects rat heart against ischemia-reperfusion injury via RhoA/ROCK pathway. PLoS One 11: e0146094, 2016.

23. Zhao J, Yu QX, Kong W, Gao HC, Sun B, Xie YQ and Ren LQ The urotensin II receptor antagonist, urantide, protects against atherosclerosis in rats. Exp Ther Med 5: 1765-1769, 2013.

24. Aboulhoda BE: Age-related remodeling of the JAK/STAT/SOCS signaling pathway and associated myocardial changes: From histological to molecular level. Ann Anat 214: 21-30, 2017.
25. Wang L, Li J and Li D: Losartan reduces myocardial interstitial fibrosis in diabetic cardiomyopathy rats by inhibiting JAK/STAT signaling pathway. Int J Clin Exp Patho 8: 466-473, 2015.

26. Ahn JH, Choi YS and Choi JH: Leptin promotes human endometriotic cell migration and invasion by up-regulating MMP-2 through the JAK2/STAT3 signaling pathway. Mol Hum Reprod 21: 792-802, 2015.

27. Wang L, Xu YX, Du XJ, Sun QG and Tian YJ: Dynamic expression profiles of MMPs/TIMPs and collagen deposition in mechanically unloaded rat heart: Implications for left ventricular assist device support-induced cardiac alterations. J Physiol Biochem 69: 477-485, 2013.

28. Guo $\mathrm{C}$ and Piacentini L: Type I collagen-induced MMP-2 activation coincides with up-regulation of membrane type 1-matrix metalloproteinase and TIMP-2 in cardiac fibroblasts. J Biol Chem 278: 46699-46708, 2003.

29. Ambale-Venkatesh B, Liu CY, Liu YC, Donekal S, Ohyama Y, Sharma RK, Wu CO, Post WS, Hundley GW, Bluemke DA and Lima JAC: Association of myocardial fibrosis and cardiovascular events: The multi-ethnic study of atherosclerosis. Eur Heart J Cardiovasc Imaging 20: 168-176, 2019.

30. Liu CY, Heckbert SR, Lai S, Ambale-Venkatesh B, Ostovaneh MR, McClelland RL, Lima JAC and Bluemke DA: Association of Elevated NT-proBNP with myocardial fibrosis in the Multi-Ethnic study of atherosclerosis (MESA). J Am Coll Cardiol 70: 3102-3109, 2017.

31. Xing XQ, Xu J, Lu XW, Huang Y and Zhu PL: Effects of losartan and simvastatin on collagen content, myocardial expression of MMP-2 mRNA, MMP-9 mRNA and TIMP-1 mRNA, TIMP-2 mRNA in pressure overload rat hearts. Zhonghua Xin Xue Guan Bing Za Zhi 37: 887-891, 2009 (In Chinese).

32. Al-Rasheed NM, Al-Oteibi MM, Al-Manee RZ, Al-Shareef SA, Al-Rasheed NM, Hasan IH, Mohamad RA and Mahmoud AM: Simvastatin prevents isoproterenol-induced cardiac hypertrophy through modulation of the JAK/STAT pathway. Drug Des Devel Ther 9: 3217-3229, 2015.

33. Cho HJ, Park JH, Nam JH, Chang YC, Park B and Hoe HS: Ascochlorin suppresses MMP-2-mediated migration and invasion by targeting FAK and JAK-STAT signaling cascades. J Cell Biochem 119: 300-313, 2018.

This work is licensed under a Creative Commons Attribution-NonCommercial-NoDerivatives 4.0 International (CC BY-NC-ND 4.0) License. 